\title{
On hygrophany of basidiocarp in the genus Clitocybe Kummer
}

\author{
HarriHarmaja \\ Department of Botany, University of Helsinki, Helsinki, Finland.
}

While preparing a monograph on the genus Clitocybe Kummer in Fennoscandia I have become acquainted with a phenomenon called hygrophany. In connection with pure taxonomical studies I have had to pay special attention to it and will in the following make some contribution to the knowledge of this phenomenon. The genus Clitocybe is very suitable for studying hygrophany because it includes both hygrophanous and non-hygrophanous species as well as some intermediate types.

The term hygrophanous was probably coined by E. Fries who used it for the first time in 1836 in his «Epicrisis e.g. in the division of the tribus Clitocybe and the genus Cortinarius. Since his time the term has been well established in mycological literature. It is remarkable, however, that the literature records no attempts to search for the reasons why «the cap gets darker when water-soaked and fades beginning from the centre when

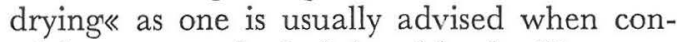
sulting a mycological hand-book. However, some researches have been made on the water economy of fleshy fungi, especially that of Pieschel (1924), in connection with which some aspects of the phenomenon have been dealt with.

When studying hygrophany I have examined the anatomy of the fruit-body and studied macroscopically the soaking and transpiration of water of various parts of the basidiocarp, both in whole fruit-bodies and in parts removed from them.

My definition of hygrophany (in a broad sense) is very simple and is but slightly modified from that of LoHWAG (1941 [1965]):
Fungal tissue is hygrophanous when it gets darker when absorbing capillary water into intercellular spaces, and paler again when the intercellular water gets transpired and the intercellular spaces get filled with air. Accordingly, a necessary qualification for the tissue to be hygrophanous is that it be spongy and thus be able to absorb water by capillary attraction into the intercellular spaces and to transpire that «extra« water more or less easily.

Pieschel (op.c.), whose studies seem to have included at least one hygrophanous species of Clitocybe, has shown that the method of water uptake described above is by no means restricted to hygrophanous species. The fruit-bodies of the latter seem, however, to be able to bind more extrahyphal water than those of non-hygrophanous species. Accordingly, the tissue does not immediately darken (= be hygrophanous) when absorbing capillary water, but the amount of water must apparently be rather great for the colour change to be observable. Physiologically, the distinction between hygrophanous and nonhygrophanous tissues is thus not very precise. For taxonomical purposes it is, however, rather practical and valuable.

In my definition I have used the word «tissue because I have found that the waterabsorbing abilities of different parts of the fruit-body are different, and they accordingly must be dealt with separately. Hygrophanous tissues are very common in fungal fruit-bodies among Basidiomycetes as well as Ascomycetes, not excluding the thalli of Lichenes.

In Clitocybe the cortex of the stipe, the lowermost tramal layer of the cap, the cutis 
and the gills are hygrophanous in most, if not all, Fennoscandian species. The fact that these tissues are hygrophanous in species with non-hygrophanous cap, too, has been ignored earlier, probably because of their thinness.

The fundamental taxonomical differences between various taxa of Clitocybe are, however, grounded upon the water-absorbing abilities of the bulk of the fruit-body, that is, the flesh of the cap and the stipe. The flesh, when hygrophanous, begins to fade (dry) in a regular manner, at first in the joint of the stipe and the cap (see later). These inner parts of the fruit-body are hygrophanous in all species of the subgenus Pseudolyophyllum Singer but only in some species of the subgenus Clitocybe s. str. When the flesh is hygrophanous, so is the whole fruit-body, often even the basal tomentum.

In $C$. alexandri and $C$. inornata the flesh is mosaic-like partially watery and it does not fade in a regular way. The flesh of these species is accordingly not considered truly hygrophanous.

There seems to be no correlation between the anatomy and the hygrophanous resp. nonhygrophanous characters of the flesh: in both cases the hyphae may be loosely interwowen or parallel, the pigments may be intracellular and/or intercellular and/or encrusted, the flesh may be rather thick or very thin. The hyphae of the flesh are almost equally broad in all Fennoscandian species of Clitocybe. To study the different abilities of different tissues and taxa to absorb interhyphal capillary water is not within the province of a taxonomist but the reason seems to lie in the different chemical and/or physical composition of the hyphal walls. The walls or substances secreted by the hyphae may diminish the surface tension of water resp. they may repel water.

The difference in colour of fungal tissue when wet resp. faded is not a unique phenomenon. It is also observable in probably all porous lifeless materials: e.g., various kinds of soil as well as the paper used for newspapers get darker when they become wet. The explanation of this is a physical one: materials absorb/reflect light in a different manner when they are homogeneously mixed with water resp. air. As already established by Pieschel (op.c.), hygrophanous fungal tissue reflects less light when wet than when faded and is therefore darker to the human eye in the former case.

The most striking and famous character of totally hygrophanous species is the regular drying (fading) of the cap, which begins from the centre. This is what is usually understood by the term «hygrophanous is accordingly considered hygrophanous onty when it fades regularly beginning from the centre. So is the case in Clitocybe when all the tissues of the fruit-body are hygrophanous. The definition of the hygrophany of the cap is thus different from that of a tissue because the cap consists of various kinds of tissues. When the cap is hygrophanous the fruit-body can be considered to be hygrophanous in the strictest meaning. This character of the cap has a great importance in delimiting taxa of Agaricales, e.g. the subgenera of Clitocybe and Cortinarius. The cap of Clitocybe clavipes and the young caps of $C$. candicans and C. radicellata, however, do not fade, or not regularly, at least, though all their tissues are hygrophanous.

The reason why the cap in hygrophanous species dries in the regular manner beginning from the centre, seems to be unknown in the literature. I have worked out a hypothesis on it when studying the Clitocybe species, and this explanation may be valid in other genera, too: the regular fading is due to the anatomical characters of the fruit-body as well as the physical laws of cohesion and adhesion, and capillary attraction.

The cutis and the lowermost tramal layer of the cap, which continues as the cortex of the stipe, are composed of tightly parallel hyphae which are, the lowest tramal layer of the cap excluded, narrower, too, than the broad and often loosely interwoven hyphae of the inner flesh of the cap and the stipe, which are surrounded by the first-named tissues. The cutis is, however, sometimes composed of rather interwoven hyphae, but these are in every case narrower than those of the flesh (a more detailed description of the anatomy of the Clitocybe species will be given in my future monograph). All in all, the hyphal walls in these «cortical« layers are accordingly more densely situated and have a greater surface per areal unit than those of the hyphae of the inner parts, that is, the flesh. From this it follows that in those layers named above the power of adhesion between the hyphal walls and water molecules is 
greater per areal unit than in the flesh proper. The cortical layers accordingly do not let the water get transpired easily but bind it more strongly than the flesh. This is perhaps the reason why these layers only are watery and hygrophanous in non-hygrophanous species the flesh of which is not hygrophanous. The watery outermost layers of most, if not all, Fennoscandian species of Clitocybe seem to store water and protect the fruitbody from excessive transpiration. The layers are thus analogous to the slimy coating of cap and stipe of many fungi. Pieschel (op.c.) has observed that often the tight cortex of the stipe effectively prevents the inner parts from losing their water by transpiration.

The inner flesh accordingly transpires the interhyphal water it contains before the cortical layers. The cap of Clitocybe species gets thinner towards the margin. This is for the most part due to the inner flesh getting thinner and the last-named may be almost lacking near the very margin. The strongly water-binding uppermost (the cutis) as well as the lowermost tramal layer are about equally thick everywhere in the cap and thus their proportion in the cap gets greater towards the margin. It appears now that also the water in the spongy inner flesh is to some degree prevented from getting transpired, the more the nearer the cap margin it is. This in turn results from cohesion between the «tightly sitting « water molecules of the cortical layers and those of the middle flesh. The binding influence of the powers of cohesion on the water in the flesh is of course greatest where the outermost layers are nearest each other, that is, gradually towards the cap margin. It is accordingly clear that it is in the joint of the cap and the stipe, where the flesh is often least compact and especially spongy, too, that the water binding effect of the tight cortical layers is at its minimum and the water of the flesh at first gets transpired and/or begins to run towards the cap margin.

This theory is supported by my observation that the gills, too, begin to fade from their thickest part, the base. The principal anatomical construction of the gills resembles rather much that of the cap: the outermost layer of the gill trama, the hymenopodium is composed of thinner hyphae than the middle trama, it is essentially the latter that gets thinner towards the gill edge, and the hyp- hae of the trama run more loosely (often they are almost interwoven) in the gill base (more detailed description in the monograph).

As described above, it is probable that a part of the water in the inner flesh runs radially from the cap centre towards the margin before it gets transpired, because the extreme margin of the cap in dry basidiocarps is often darker than the rest of the cap. This water flow may be due to capillary attraction. This difference in colour, also observed in non-hygrophanous species, viz. seems to be due to the fact that when studied under the microscope there is an unusually high concentration of intercellular pigment in the interhyphal spaces of the cap margin. The pigment may have been washed away from other parts of the fruit-body. Pieschel (op.c.) has demonstrated experimentally that in agarics there is often a flow of water from the centre of the cap towards the margin.

The fading of the cap is principally the same physical phenomenon that occurs in tubes with running water: in wide tubes the walls do not much retard the running of water, but the narrower the tube is, the more its walls affect the running of the water by means of adhesion and cohesion. The cap from the centre towards the margin may be compared with a gradually narrowing tube.

In old fruit bodies of some non-hygrophanous species of Clitocybe (e.g. C. gibba) there may be watery hygrophanous spots in the cap or it may be almost entirely watery, but in such cases it fades more or less irregularly and the cap as a whole cannot be considered hygrophanous in the strict sense. The hyphae in such very old fruit bodies have probably undergone chemical and/or physical changes or they may even be dead, and for such reasons they do not function normally and cannot control the type of water economy peculiar to that species.

The meaning of being hygrophanous for the fruit body is not known. It is interesting that the hygrophanous species in Clitocybe and other genera seem to have smaller fruit bodies o nthe average than nonhygrophanous species.

\section{LITERATURE}

Lohwag, H., 1941 [1965]: Anatomie der Ascound Basidiomyceten. - Handb. Pflanzenanat. VI: $8,1-572$.

Pieschel, E., 1924: Ueber die Transpiration und Wasserversorgung der Hymenomyceten. Bot. Arch. 8, 64-104. 